\title{
Prediction of Marital Satisfaction Based on Personality Traits and Sense of Humor among Employed Women
}

\author{
Kāzem Gerām \\ PhD in Psychology, Faculty Member of Azad University, Arak \\ Email:k-geram@iau-arak.ac.ir
}

\section{Doi:10.5901/mjss.2016.v7n4s1p123}

\section{Abstract}

The aim of the present study is to predict marital satisfaction in employed women based on personality traits and sense of humor. This study is a correlational study. The statistical populations include all of the employed women in high schools of District 1 of Arak city (Iran). The sample and the sample size were selected randomly in clustering form among all schools of Arak city the five of which were chosen in which 250 employed women were selected as sample size. In this study, MIS, NEO personality Inventory and Martin's Humor Test were used. To test the hypotheses and homogeneity of variances, Pearson correlation test and Levin test were used respectively. By SPSS software, the obtained data was analyzed using Pearson Coefficient. The results of this study demonstrated that there was a significant relationship between marital satisfaction and humor. This could be concluded that an increase in personality traits and sense of humor lead to an increase in marital satisfaction in employed women.

Keywords: marital satisfaction, personality traits, sense of humor, employed women

\section{Introduction}

Family is introduced as an institution or social institution which is come into existence by matrimonial alliance between men and women. Family members including couples, children and sometimes grandparents and grandchildren live together based on peaceful coexistence, peace, intimacy, understanding and cooperation. Families are usually small units of at least two or three persons. It is regarded as one of the most important social institute, the first source for raising and educating the generations, the greatest source of happiness and the richest source of affections. Healthy and productive interactions among human beings and expressing love, intimacy and intimacy and communion toward others are among the aspects of human's social life. Human being has multi-dimensional personality. Desires to live in social life and looking for union with others form the important parts of the complex entity of humanity. By studying complicated dimensions of human behavior and his mental world, psychologists and other specialists of behavioral science provide salutary strategies and information for humanity's mental and physical health through which he/she could live in peace and comfort. (Ahmadi, 2006).

Although there are some advantages about technology and information, however, they created a huge gap in today's life. Growing of pessimism and depression, despair, frustration, decrease in age of suicide and increase in divorce, crime and many other socio psychological problems are irrefutable facts which show that joy is disappearing in human society (Rolumi, 1967, quoted in Shafiabadi, 2005). Intimacy is invaluable in marriage because it strengthens couples' commitment and is positively associated to marital satisfaction. It is often described as a dynamic process. According to Hotfield (1968), intimacy is expressed as a process in which people try to be closer to each other. Personality trait theory is one of the most important theories in study of characteristics. Based on this theory, peoples' personality is composed of broader characteristics and traits. Most probably, we may mention about someone's sociability, kindness and calmness. By "trait" we mean a relatively stable characteristic which causes people to act in certain ways (Fist, 2002; trans. Seyed Mohamadi, 2013). Unlike other personality characteristics, such as psychological and humanistic theories, personality trait theory centers on difference between individuals. Combination and interaction of different features shape a person's character and this is a unique situation for every individual. Personality trait theory revolves around identifying and measuring these individual traits and characteristics (Shults, 2013; trans. Seyyed Mohammadi, 2013).

Characteristic has a large scope, because it has very complex and various dimensions. For discovering the humanity's character, many efforts have been done some of which are impractical, superstitious and few are scientific 
and valid. In common language, character has other meanings. For example, when it is said that someone is personable, it means that he has qualities that can influence other people or he has special dignity. Along similar lines, depersonalization means having negative attributes. The term character is known as well-known and qualified faces in areas such as political, scientific, artistic characters etc. "Character" is an abstract concept and similar to energy in physics, it is not visible; it is presumed through combination of behavior, thoughts, motivation, emotion etc. Character differentiates between the total populations (humans), but this difference is just in some of the "characteristics and features" (Fist, 2002; trans. Seyed Mohamadi 2013).

According to Sternberg (1987), intimacy is a kind of feeling which creates affiliation, closeness and contact. In facing with stressful situations, funny people show less negative moods than others. Humor is an effective way to deal with negative emotions such as anger, sadness, and depression. People with sense of humor are more likely to take more active positions than their negative excitements and they try to dominate them. In turn, people with no sense of humor are more passive and they are able not to control their negative feelings. Most of people with sense of humor are more in shape. Studies have demonstrated that sense of humor causes the increase of immune system which paves the way for people to overcome stressful situations in their daily life. Sense of humor helps us react to stressful situations easily rather than with fear or panic. Sense of humor provides us an opportunity to escape from problems and have time to look at other possible solutions. Another advantage of sense of humor is that when we are in a happy mood, others are more likely to help and support us. The healthiest type of sense of humor is to be gentle, i.e. not to take ourselves too seriously (Ahmadi, 2012). Researches have indicated that sexual dissatisfaction or social problems such as crime, rape, infidelity and mental illness in couples and sense of absurdity and incongruity are closely related to each other (Bahreynian and Kermani, 2010).

One of the most influential factors in stability and also mental health of families and children is marital satisfaction. Several factors affect marital satisfaction and most important factors in success of families is mental and intellectual growth, similarity of interests and ideology, similarity in religion, resemblance in education and social class, similarity of thoughts in sexual matters, similarity of interests in life, promptness in doing affairs and their relationship with man and woman's family.

Physical, emotional and mental health of people in the society relies on the healthiness of marital relations and sustainability of marriage. Satisfaction of a person from marital relation constitutes his satisfaction of family and satisfaction of family means satisfaction of life; therefore, it will facilitate growth and development and improve material and spiritual growth of the society.

Given the fact that all of the psychologists, sociologists and religions consider family and marital relationship as sacrosanct issues, and also the fact that family is not a place for dissatisfaction, these questions come into mind that 'Why couples are unsatisfied? Which factors can affect their satisfaction? Can attachment methods affect their satisfaction? (Olia, 2008). According to the current study, this question is presented: 'Is there any relationship between marital satisfaction and sense of humor in employed women?'

\section{Methodology}

According to goals the study, the overall outline of the present study is applicable and correlational. All of the woman teachers (1500 individuals) working in schools of Arak city, are working in Arak city now (2015). To choose samples and sample size, five schools were selected through random cluster sampling among all schools of Arak city.

\section{Measuring Instruments}

Five-dimension personality trait assessment questionnaire (NEO)

Test description: NEO questionnaire is one of the newest questionnaires to evaluate personality structures based on factor analysis. Today, based on its analysis of the factors and covering five main factors, this test is considered as a comprehensive model. Its prevalent use in evaluation of healthy people and clinical practice can be regarded as one of the most appropriate tools for personality assessment. This test can be regarded as one of the most comprehensive personality assessment tests in evaluation of characteristics due to its various examinations on various age groups in different cultures. This test has been the subject of studies during the last 15 years in clinical samples and healthy adults. Therefore, its usefulness has been evaluated in course of clinic and investigations. NEOPL-R personality inventory test is replaced by NEO which had been prepared by MacCrae and Costa. This questionnaire measures five personality traits and six characteristics in each factor, i.e. it measures 30 characteristics, and accordingly, it provides comprehensive assessment of personality. This questionnaire has two forms, one of them is (S) for personal reports and it has 240 
questions in 5 points from 'Strongly Agree' to 'Strongly Disagree' which is graded by the subjects themselves and it is suitable for men and women of all ages. Other form is (R) or revised form and it is based on observer's ratings. This form has the same 240 questions; however, it begins with third person. Form (R) can be used independently to assess personality and also as a complement for personal reports (S) or its validity can be used (Grusi Farshi, 2001). This questionnaire has a short form called (NEO-FFI) which has 60 items and is used to assess five personality traits. If test execution time is limited and general information is sufficient, this questionnaire is used. On the other hand, application of this test is very affordable and its scales are highly reliable(Graucy farshi,2001)

\subsection{Marital Intimacy Scale (MIS)}

This scale 1 was first developed by Thompson and Walker. It has 17 questions and aims to measure marital intimacy in couples. The questionnaire scores range from 1 (Never) to 7 (Always) the highest of which shows more intimacy. Its alpha coefficient is $91 / 0$ to $97 / 0$ and it has good consistency (Walker and Thompson 1983; quoted in Sanaei, 2000). By adding the scores of the questions and dividing them by 17 , test score is obtained.

The questionnaire was first checked by 15 advisers and 15 couples in order to determine the validity and content (Validity and content are confirmed). The questionnaire was conducted on 100 couples in Isfahan city who were selected randomly. The reliability coefficient of the scale which was obtained through Cronbach's alpha was 96/0 which indicates that the questionnaire has acceptable reliability. Calculating the reliability by omitting each questions show that the act of omitting does not have notable influence on reliability (Etemadi et al., 2006)

\subsection{Sense of Humor Questionnaire}

Martin's Sense of humor test has 25 items. In order to have a quantitative result, the questions are designed in 7-point scales of 'Strongly Agree' (point 7) to 'Strongly Disagree' (point 1). The total minimum score of each participant is 25 and the maximum is 175 and for each dimensions, 5 is the minimum and 25 is the maximum. Thus, high score represents greater sense of humor.

Reliability and validity of sense of humor scale: In order to evaluate the reliability of the test, the questionnaire was fist tested by 40 (20 men and 20 women) participants who were chosen among the population by simple random sampling. The internal consistency was $88 \%$ by using alpha Cronbach. Validity of this test was obtained by factor analysis (respectively for five factors: 46/0, 59/0, 49/0, 39/0, 59/0) which is an acceptable amount (Khoshuei, 2010).

\section{Data Analysis}

Table 1. Qualitative Scores of Personality Traits

\begin{tabular}{cccccccc}
\hline Group & Variable & Number & Average & Standard deviation & Standard error & Maximum score & Minimum score \\
\hline Employed women & Personality traits & 250 & $144 / 33$ & $8 / 321$ & $0 / 917$ & 168 & 127 \\
\hline
\end{tabular}

According to Table 1, average score in personality trait questionnaire was $144 / 23$, its standard deviation was $8 / 321$, standard error was 0/917, maximum score was 168 and minimum score was 127.

Table 2. Results of Sense of Humor Questionnaire

\begin{tabular}{|c|c|c|c|c|c|c|c|}
\hline Group & Variable & Number & Average & Standard deviation & Standard error & Maximum score & Minimum score \\
\hline Employed women & Sense of humor & 250 & $270 / 33$ & $7 / 301$ & $0 / 432$ & 320 & 258 \\
\hline
\end{tabular}

According to Table 2, average score was 270/33, standard deviation was 7/301, standard deviation was 0/432, maximum score was 320 and minimum score was 258.

Table 3. Results of Assessment of Marital Satisfaction

\begin{tabular}{|c|c|c|c|c|c|c|c|}
\hline Group & Variable & Number & Average & Standard deviation & Standard error & Maximum score & Minimum score \\
\hline Employed women & Marital satisfaction & 250 & $288 / 13$ & $6 / 431$ & $0 / 456$ & 350 & 280 \\
\hline
\end{tabular}

1 This scale was translated by Sanaei (2000) 
According to Table 3, average scores in marital satisfaction was $288 / 13$, standard deviation was $6 / 431$, standard error was 0/456, maximum score 350 and minimum score was 280.

Table 4. Levene's Test for Homogeneity of Variances

\begin{tabular}{lccc}
\hline & $F$ & DF & sig \\
\hline Personality trait & $0 / 166$ & 250 & $0 / 685$ \\
Sense of humor & $2 / 272$ & 250 & $0 / 136$ \\
Marital satisfaction & $0 / 184$ & 250 & $0 / 284$ \\
\hline
\end{tabular}

According to Table 4, $\mathrm{F}$ and significance level (sig=0/685, $\mathrm{F}=0 / 166)$ variances are equal. According to Table 4, $\mathrm{F}$ and significance level (sig=0/136, $\mathrm{F}=2 / 272)$ variances are equal. According to Table 4, $\mathrm{F}$ and significance level (sig=0/284, $\mathrm{F}=0 / 184)$ variances are equal.

\section{Main Hypothesis}

There is significant relationship between personality traits and sense of humor with marital satisfaction.

\begin{tabular}{lccc}
\hline & Correlation coefficient & Sig & $\mathrm{N}$ \\
\hline Personality trait & 1 & & 250 \\
Marital satisfaction & $0 / 871$ & $0 / 025$ & 250 \\
\hline
\end{tabular}

According to the table, correlation coefficient between personality trait and marital satisfaction is 0/871 which shows that this coefficient is significant in 01/0 level. It can be argued that there is a direct relationship between personality trait and marital satisfaction. With the increase of personality trait, the increase of marital satisfaction occurs. The calculated correlation coefficient for personality trait is significant and the first hypothesis is confirmed.

There is a significant relationship between marital satisfaction and sense of humor in employed women.

\begin{tabular}{lccc}
\hline & Correlation coefficient & Sig & $\mathrm{N}$ \\
\hline Personality trait & 1 & & 250 \\
Marital satisfaction & 250 & $0 / 025$ & $0 / 745$ \\
\hline
\end{tabular}

According to the table, correlation coefficient between sense of humor and marital satisfaction is 0/746 which shows that this coefficient is significant in 0/01 level. It can be argued that there is a direct relationship between sense of humor and marital satisfaction. To put it this way, an increase in sense of humor score leads to an increases in marital satisfaction. The calculated correlation coefficient for sense of humor variable is significant and the first hypothesis is confirmed.

\section{Discussion and Conclusions}

The main hypothesis of the present study is that there is a significant relationship between personality traits and sense of humor in employed women. After testing the hypothesis, correlation coefficient between the scores of personality traits and marital satisfaction was 0/871 and significant in 0/01 level. In fact, it can be argued that there is a direct relationship between personality trait and marital satisfaction. It is meant to state that by increasing personality traits scores, marital satisfaction increases. Therefore, correlation coefficient for personality trait is significant and main hypothesis is confirmed. Correlation coefficient between sense of humor and marital satisfaction is 0/745 which shows that it is significant in 0/01 level. In fact, it can be argued that claimed that there is direct relationship between sense of humor and marital satisfaction. If marital satisfaction increases, the sense of humor also increases. Calculated correlation coefficient for sense of humor variable is significant and the main hypothesis is confirmed. The results of this study is in agreement with the finding of Iranian researchers such as Mehrabi (2013), Naeinian and Nikazin (2013), Zabihi (2012), Rahmati (2012), Nasr (2012), Batlani (2011), Mazarei (2010), Nia Karubi (2009), Rostami (2008), Rahimi (2008), Sanaei (1997), and foreign researchers like McKarty (2015), Ivans (2015), Tesdibl (2015), Mackarken (2015), Garland, Kayler and Fredricson (2014), Roznezvic, GrissonRibel, Jacer and Sbili (2014), Steve (2012), Mackarty (2010), Pazer (2006), Smith (2004), Mezlo (1989) and Beldwolf (1960).

By explaining the findings of the study, it can be noted that there is a direct relationship between personality traits 
and marital relationships. Personality traits have considerable impact on employed women lives. Personality traits have a considerable impact on marital relationship and empathic connections of people. It can also be declared that sense of humor and joyful relationship between husband and wives causes better relationships and provide salutary and significant impact on these relationships.

\section{References}

Ahmadi, R. (2012). Sense of humor, (5th ed.) Tehran: Madreseh,

Bahreynian, A. Yavari Kermani, M. (2010). Sexual satisfaction and life satisfaction, Journal of Psychotherapy, 52, 67

Shulz D. P., Allen, Sh. (2013). Personality theories, (10 ed.). (trans. by Seyyed Mohamadi,) Tehran: arasbaran.

Etemadi, O., Navabinejad, \& Sh, Ahmadi, A., \& Valiollah, F. (2006). Investigating the effect of marital therapy on increasing intimacy of couples referring to counseling centers in Isfahan city by Imagotrapy. News and Researches on Counseling. 19, 9-22

Jess feist \& Gregory j. feist (2002). Personality theories, (5th ed.) (trans. by Seyed Mohamadi), Tehran: Ravan Press

Khoshuei, M. (2005). Relationship between humor and mental health in 20-60 year people in Isfahan city, M. A. thesis in General psychology, Faculty of psychology and education, Islamic Azad University, Khorasgan branch

Olia, N. (2006). Investigating the effect of enhancement in marital life on marital satisfaction of couples in Isfahan, M.A thesis, University of Isfahan, Iran

Shafiabadi, A., Naseri, Gh. (2005). Theories of counseling therapy, Tehran: Daneshgahi Publication 